\title{
Safety and efficacy of prothrombin complex concentrates for the treatment of coagulopathy after cardiac surgery
}

\author{
Howard K. Song, MD, PhD, Frederick A. Tibayan, MD, Ed A. Kahl, MD, Valerie A. Sera, MD, \\ Matthew S. Slater, MD, Thomas G. Deloughery, MD, and Mick M. Scanlan, MD
}

\begin{abstract}
Objective: Coagulopathy is an important cause of bleeding after complex cardiac surgery. The conventional treatment for coagulopathy is transfusion, which is associated with adverse outcomes. We report our initial experience with the prothrombin complex concentrate FEIBA (factor VIII inhibitor bypassing activity) for the rescue treatment of coagulopathy and life-threatening bleeding after cardiac surgery.
\end{abstract}

\begin{abstract}
Methods: Twenty-five patients who underwent cardiac surgery with coagulopathy and life-threatening bleeding refractory to conventional treatment received FEIBA as rescue therapy at our institution. This cohort represents approximately $2 \%$ of patients undergoing cardiac surgery in our university-based practice during the study.

Results: The patients were at high risk for postoperative coagulopathy with nearly all patients having at least 2 risk factors for this. Aortic root replacement (Bentall or valve-sparing procedure) and heart transplant with or without left ventricular assist device explant were the most common procedures. The mean FEIBA dose was 2154 units. The need for fresh frozen plasma and platelet transfusion decreased significantly after FEIBA administration $(P=.0001$ and $P<.0001)$. The mean internationalized normalized ratio decreased from 1.58 to $1.13(P<.0001)$. Clinical outcomes were excellent. No patient returned to the operating room for reexploration. There was no hospital mortality and all patients were discharged home. One patient who had a central line and transvenous pacemaker developed an upper extremity deep vein thrombosis.
\end{abstract}

Conclusions: Our initial experience with FEIBA administration for the rescue treatment of postoperative coagulopathy and life-threatening bleeding has been favorable. Further studies are indicated to confirm its efficacy and safety and determine specific clinical indications for its use in patients undergoing cardiac surgery. (J Thorac Cardiovasc Surg 2014;147:1036-40)

Coagulopathy is a frequent complication of cardiac surgery and cardiopulmonary bypass. ${ }^{1}$ The causes of coagulopathy are multifactorial, and include excessive fibrinolysis, platelet dysfunction, and coagulation factor deficiency due to consumption and dilution, ${ }^{1-4}$ Especially after complex operations, coagulopathy is associated with bleeding and the need for blood component transfusion and surgical reexploration, all of which have been linked to adverse outcomes and prolonged length of stay. ${ }^{1,2,5-7}$ The mainstays of treatment for coagulopathy associated with cardiac surgery are antifibrinolytic drug therapy to prevent excessive fibrinolysis, and blood component transfusion to correct platelet and coagulation factor deficiencies.

From the Division of Cardiothoracic Surgery, Department of Anesthesiology and Perioperative Medicine, Division of Hematology and Medical Oncology, Oregon Health \& Science University, Portland, Ore.

Disclosures: H.K. Song currently receives support from Thoratec Inc and HeartWare Inc. All other authors have nothing to disclose with regard to commercial support. Read at the 39th Annual Meeting of The Western Thoracic Surgical Association, Coeur d'Alene, Idaho, June 26-29, 2013.

Received for publication July 1, 2013; revisions received Oct 22, 2013; accepted for publication Nov 11, 2013; available ahead of print Dec 23, 2013.

Address for reprints: Howard K. Song, MD, PhD, Division of Cardiothoracic Surgery, Mail Code L353, OHSU, 3181 SW Sam Jackson Park Rd, Portland, OR 97239

(E-mail: songh@ohsu.edu).

0022-5223/\$36.00

Copyright (C) 2014 by The American Association for Thoracic Surgery

http://dx.doi.org/10.1016/j.jtcvs.2013.11.020
These therapies, however, are frequently ineffective and are themselves associated with adverse outcomes. ${ }^{7-11}$ Therefore, there is a need for novel therapies that can effectively and safely treat coagulopathy after cardiac surgery and prevent the complications associated with it.

Several plasma-derived and recombinant coagulation factors are available for systemic administration and have been used for the treatment of coagulopathy after cardiac surgery. Experience with the use of recombinant factor VIIa is increasing and its efficacy is being demonstrated, however this has been associated with thrombotic risk and has a substantial cost. ${ }^{12-20}$ Prothrombin complex concentrates (PCCs) are plasma-derived concentrates of vitamin $\mathrm{K}$-dependent factors II, VII, IX, and X. ${ }^{21-24}$ There has been some experience with the use of PCCs to reverse warfarin anticoagulation in patients undergoing emergency cardiac surgery but PCCs have not been studied systematically for the treatment of coagulopathy after cardiopulmonary bypass. ${ }^{25-27}$ In this study, we report our initial experience with PCCs for the rescue treatment of coagulopathy and life-threatening bleeding after cardiac surgery.

\section{METHODS}

Demographic and perioperative clinical information are collected prospectively for all patients undergoing cardiac surgery at Oregon Health 


\section{Abbreviations and Acronyms \\ FEIBA $=$ factor VIII inhibitor bypassing activity \\ LVAD $=$ left ventricular assist device \\ PCC $=$ prothrombin complex concentrates}

\& Science University Hospital. An institutional pharmacy database was surveyed to identify all patients who underwent cardiac surgery and received the PCC product factor VIII inhibitor bypass activity (FEIBA; Baxter Healthcare Corporation; Deerfield, Ill) from July 2011 to October 2012. ${ }^{21}$ Twenty-five patients were identified and included in this study.

Intraoperative $\varepsilon$-aminocaproic acid was administered to all patients as a 5 -g intravenous loading dose and $30 \mathrm{mg} / \mathrm{kg} / \mathrm{h}$ infusion. An additional $5 \mathrm{~g}$ was included in the cardiopulmonary bypass machine prime. All patients underwent standard heparinization (300-400 IU/kg) before cardiopulmonary bypass and activated clotting times were maintained at greater than 480 seconds. At the conclusion of cardiopulmonary bypass, heparin was reversed with protamine sulfate at a dose based on the measured level of circulating heparin. A cell saver and cardiotomy suction were used in all cases.

Patients who were treated with therapeutic levels of warfarin at the time of surgery received fresh frozen plasma (4-6 units) before weaning from bypass. After heparin reversal, any observed coagulopathy was treated empirically with standard transfusion of platelets, fresh frozen plasma, and cryoprecipitate. Transfusion was also guided by point-of-care thromboelastography, prothrombin and activated partial thromboplastin times, and platelet count. Packed red blood cells were transfused to maintain a hematocrit greater than $21 \%$. If the surgeon noted that coagulopathy and life-threatening bleeding persisted despite conventional treatment, FEIBA was administered (1000-4000 units) as a slow intravenous push. FEIBA was only administered intraoperatively before chest closure.

Nominal data are presented as frequencies and percentages. Continuous data are reported with the mean, range, and standard deviation. Comparisons before and after administration of FEIBA (fresh frozen plasma and platelet transfusion, internationalized normalized ratio, partial thromboplastin time, and fibrinogen) were performed with the two-tailed Student $t$ test.

Institutional review board approval was obtained for this study. The requirement for individual consent was waived.

\section{RESULTS}

Twenty-five patients who received FEIBA as rescue therapy after failing conventional treatment of coagulopathy were identified. This represents approximately $2 \%$ of all patients undergoing cardiac surgery at our institution during the study period. Demographic and clinical data are summarized in Table 1. The mean age of the patients was relatively low for an adult cardiac surgery population (49.6 years) and reflects the types of surgical procedures performed. All patients had either an aortic procedure, a left ventricular assist device (LVAD) implant, or a heart transplant with or without an LVAD explant. There were no coronary artery bypass procedures performed in this group. The preoperative hematologic profile of most patients was unremarkable, with the exception of the international normalized ratio. Twelve patients were anticoagulated with warfarin at the time of their surgery.
In all instances, these patients had heart failure and required anticoagulation because of ongoing LVAD support or were anticoagulated because of their risk or previous history of left ventricular thrombus. The urgent or emergency nature of their procedures did not allow time for warfarin to be stopped before their surgery. Patients with an LVAD admitted for heart transplantation did receive a dose of intravenous vitamin $\mathrm{K}$ in the hours before their heart transplant as part of our institutional protocol.

All patients had at least 1 risk factor for the development of coagulopathy after cardiac surgery, and most had multiple risk factors (Table 2). Most risk factors were related to the patient's clinical condition or planned procedure and were apparent before the operation. The most common risk factors for coagulopathy were prolonged cardiopulmonary bypass time, preoperative anticoagulation, aortic surgery, and redo sternotomy.

All patients had complete reversal of heparinization with protamine after cessation of cardiopulmonary bypass. Sufficient protamine was administered so that circulating heparin levels were undetectable and activated clotting times were returned to baseline levels. Coagulopathy was then treated with conventional blood product transfusion. Blood product transfusion was typically empiric with additional guidance from point-of-care thromboelastography, platelet counts, and prothrombin times. If the surgeon noted that a patient had ongoing coagulopathic bleeding despite these measures and no clear surgical source could be identified, FEIBA was administered as a rescue treatment. The mean FEIBA dose was 2154 units (Table 3). Early in our experience, we gave FEIBA in 1000-unit increments to achieve the desired hemostatic effect. Later, we simply administered 2000 units in a single dose, which was typically sufficient. Eighteen patients received 2000 units.

Blood product use decreased substantially after FEIBA administration (Table 3). Patients received a mean fresh frozen plasma transfusion of 4.76 units before FEIBA and 0.68 units after FEIBA $(P=.0001)$. Platelet transfusion was reduced from 2.76 units to 0.52 units after FEIBA administration $(P<.0001)$. Seventeen patients received no further plasma or platelet transfusion in the postoperative period after FEIBA administration. Cryoprecipitate was only given to 2 patients in the series. The mean packed red blood cell transfusion for patients in the perioperative period was 1.16 units and 16 patients did not receive red blood cell transfusion. No recombinant coagulation factors such as factor VIIa were given to any patients in the series.

Pre- and post-FEIBA dosing coagulation studies were available for comparison in 17 patients (Table 4). The international normalized ratio was significantly reduced in these patients without a notable change in partial thromboplastin time or fibrinogen levels. Blood loss was not measured intraoperatively. In the first 3 postoperative days, the mean chest tube drainage was 664,549 , and 
TABLE 1. Demographic and preoperative clinical data

\begin{tabular}{lc}
\hline \multicolumn{1}{c}{ Characteristic } & Value \\
\hline Patient data & \\
Mean age, y (range) & $49.6(28-72)$ \\
Male gender, $\mathrm{n}(\%)$ & $20(80)$ \\
Procedure, $\mathrm{n}(\%)$ & \\
Urgent status & $14(56)$ \\
Emergency status & $1(4)$ \\
Redo sternotomy & $10(40)$ \\
Bentall procedure & $5(20)$ \\
Valve-sparing aortic root replacement & $3(12)$ \\
Valve replacement or repair & $3(12)$ \\
Ascending aortic replacement & $3(12)$ \\
Aortic arch replacement & $2(8)$ \\
LVAD explant & $6(24)$ \\
LVAD implant & $5(20)$ \\
Heart transplant & $9(36)$ \\
Preoperative hematologic studies & \\
Mean hemoglobin $(\mathrm{g} / \mathrm{dL})$ & 13.1 \\
Mean platelet count $(\times 1000 / \mu \mathrm{L})$ & 191 \\
Mean international normalized ratio & 1.54 \\
\hline$L V D D$ Left ventricular assist device.
\end{tabular}

$331 \mathrm{~mL}$ (Table 5), which is similar to what is observed in our patients who do not develop coagulopathy.

The clinical outcomes in this series of complex patients were excellent. All patients had their chests closed primarily without packing. No patients were returned to the operating room for reexploration for bleeding. There was no operative (30-day) mortality. The mean intensive care unit stay was 7 days and the mean total hospital length of stay was 12.8 days. All patients were discharged to home. One patient who had transvenous implantable cardioverter defibrillator leads before heart transplantation and a central line placed at the time of surgery developed an upper extremity deep vein thrombosis. There were no other thrombotic complications.

TABLE 2. Preoperative risk factors for coagulopathy and bleeding

\begin{tabular}{lc}
\hline \multicolumn{1}{c}{ Risk factor } & Number $(\%)$ \\
\hline Marfan syndrome & $4(16)$ \\
Preoperative anticoagulation & $12(48)$ \\
Redo sternotomy & $10(40)$ \\
Heart transplant & $9(36)$ \\
Aortic surgery & $11(44)$ \\
LVAD explant & $6(24)$ \\
LVAD implant & $5(20)$ \\
Cardiopulmonary bypass $>180$ min & $14(56)$ \\
Circulatory arrest & $2(8)$ \\
Number of risk factors & \\
1 risk factor & $2(8)$ \\
2 risk factors & $7(28)$ \\
3 risk factors & $10(40)$ \\
4 or more risk factors & $6(24)$ \\
\hline
\end{tabular}

LVAD, Left ventricular assist device.
TABLE 3. FEIBA dosing and blood product use

\begin{tabular}{|c|c|}
\hline Blood product use & Dosing \\
\hline \multicolumn{2}{|l|}{ FEIBA } \\
\hline Mean FEIBA dose (units) & 2154 (range, 1000-4000; SD, 781) \\
\hline \multicolumn{2}{|l|}{ Transfusion } \\
\hline $\begin{array}{l}\text { Mean FFP transfusion before } \\
\text { FEIBA (units) }\end{array}$ & 4.76 (range, 2-10; SD, 2.5) \\
\hline $\begin{array}{l}\text { Mean FFP transfusion after } \\
\text { FEIBA (units) }\end{array}$ & $0.68($ range, $0-7 ; \mathrm{SD}, 1.5 ; P=.0001)$ \\
\hline $\begin{array}{l}\text { Mean platelet transfusion } \\
\text { before FEIBA (units) }\end{array}$ & 2.76 (range, $1-5 ; \mathrm{SD}, 1.0)$ \\
\hline $\begin{array}{l}\text { Mean platelet transfusion after } \\
\text { FEIBA (units) }\end{array}$ & 0.52 (range, $0-5 ; \mathrm{SD}, 1.1 ; P<.0001)$ \\
\hline
\end{tabular}

\section{CONCLUSIONS}

Coagulopathy is an important risk factor for bleeding and transfusion and is associated with both early and late morbidity in patients undergoing cardiac surgery. ${ }^{1,2,5,6}$ This study describes our early experience with FEIBA, a novel treatment for coagulopathy in patients undergoing cardiac surgery who have failed conventional treatment for this. Our experience has been favorable, with dramatic improvement in coagulation, reduction in transfusion requirements, and avoidance of reexploration for ongoing bleeding. The safety profile of the treatment has also been reassuring, with a thrombotic complication occurring in only 1 patient who had other risk factors predisposing him to this.

FEIBA is composed of factors II, IX, and X, which are mostly nonactivated, and small amounts of factor VIIa. ${ }^{21}$ It acts on steps in the intrinsic and extrinsic coagulation pathways to facilitate thrombin generation on the platelet surface. ${ }^{28}$ Given the common use of recombinant factor VIIa for similar indications in patients undergoing cardiac surgery, our positive experience with FEIBA, which contains factor VIIa, is perhaps unsurprising. We chose to use the FEIBA PCC preparation because it contains factor VIIa, unlike other PCC preparations available in the United States. Recombinant factor VIIa administration has been associated with a significant incidence of thrombotic complications, however. ${ }^{16}$ FEIBA may have an advantage in this regard because it contains multiple coagulation factors and acts on both coagulation pathways, possibly leading to a reduced dosing requirement compared with the pharmacologic levels achieved with factor VIIa treatment. The typical dose used in our series was approximately 20 units $/ \mathrm{kg}$ which is only $20 \%-50 \%$ of that used for its approved indication in hemophiliacs with inhibitors. ${ }^{29} \mathrm{We}$ have also observed that the effect of FEIBA administration on the international normalized ratio was less dramatic than that typically seen with recombinant factor VIIa even though the clinical hemostatic effect in our experience has 
TABLE 4. Pre- and post-FEIBA coagulation profiles

\begin{tabular}{|c|c|c|c|c|c|}
\hline \multicolumn{2}{|c|}{ International normalized ratio } & \multicolumn{2}{|c|}{ Partial thromboplastin time (seconds) } & \multicolumn{2}{|c|}{ Fibrinogen $(\mu \mathrm{g} / \mathrm{L})$} \\
\hline Pre-FEIBA & Post-FEIBA & Pre-FEIBA & Post-FEIBA & Pre-FEIBA & Post-FEIBA \\
\hline $\begin{array}{l}1.58 \text { (range, 1.12-2.29; } \\
\quad \mathrm{SD}, 0.24 \text { ) }\end{array}$ & $\begin{array}{c}1.13 \text { (range, } 0.92-1.43 ; \\
\text { SD, } 0.15 ; P<.0001)\end{array}$ & $\begin{array}{l}36.11 \text { (range, 29.3-64.3; } \\
\mathrm{SD}, 8.8 \text { ) }\end{array}$ & $\begin{array}{l}35.36 \text { (range, } 28.6-55.3 ; \\
\text { SD, } 7.5 ; P=.8)\end{array}$ & $\begin{array}{l}272.9 \text { (range, 130-377; } \\
\text { SD, 74) }\end{array}$ & $\begin{array}{c}263.8 \text { (range, 167-396; } \\
\text { SD, 69; } P=.51 \text { ) }\end{array}$ \\
\hline
\end{tabular}

FEIBA, Factor VIII inhibitor bypassing activity; $S D$, standard deviation.

been similar. The cost of FEIBA administration in our center was also substantially lower than that associated with the use of recombinant factor VIIa. ${ }^{30}$

Procoagulants such as FEIBA and recombinant factor VIIa are not approved for patients undergoing cardiac surgery in the United States. For this reason, we have used FEIBA cautiously, as a rescue treatment only in a small subpopulation of our patients who had ongoing coagulopathy and bleeding despite conventional transfusion treatment. This determination was made by the surgeon in the operating room before chest closure, so that the coagulopathy and the response to treatment could be directly observed. We believe this is the safest setting to administer procoagulants to avoid overuse and thrombotic complications. This policy has led to a change in our practice in that the transfusion and resuscitation phase of care of these complex cases is initiated and completed in the operating room. Patients do not leave the operating room with ongoing coagulopathy but have this addressed completely before chest closure. We believe this practice contributed to the excellent outcomes observed: all patients had their chest closed without packing, no patients required reexploration, and red blood cell transfusion was avoided altogether in 16 patients.

Most patients in this study had multiple risk factors for coagulopathy. Potentially, these patients could be prospectively identified as being at high risk for requiring procoagulants such as FEIBA or recombinant factor VIIa to stop bleeding. As our experience with procoagulants increases, we may be able to prophylactically treat certain categories of high-risk patients, such as those undergoing aortic dissection repair under circulatory arrest, to avoid or limit transfusion rather than using procoagulants solely as a rescue therapy. ${ }^{31}$ In the future, this may be the most efficient way to minimize transfusion and its deleterious effects on patients undergoing complex cardiac procedures.

This study does have several limitations. It is a retrospective study of a relatively small number of patients. Patients were relatively young and no patients had

TABLE 5. Postoperative chest tube drainage volume

\begin{tabular}{lccc}
\hline & \multicolumn{3}{c}{ Chest tube drainage volume (mL) } \\
\cline { 2 - 4 } Postoperative day & Mean & Range & Standard deviation \\
\hline 1 & 664 & $145-1985$ & 430 \\
2 & 549 & $170-1260$ & 339 \\
3 & 331 & $100-1040$ & 222 \\
\hline
\end{tabular}

coronary artery bypass grafting. Their risk for thrombotic complications was therefore likely lower than that of a typical cardiac surgery population. Different PCCs on the market contain coagulation factors in varying amounts and our experience may not necessarily be generalized to all PCC formulations. In addition, we did not collect cost data, and therefore were unable to provide an economic analysis of this treatment strategy. Despite these limitations, our early experience suggests that this approach holds promise for the treatment of coagulopathy in some populations of patients undergoing cardiac surgery. Further study of procoagulants in patients undergoing cardiac surgery is warranted.

\section{References}

1. Despotis G, Eby C, Lublin DM. A review of transfusion risks and optimal management of perioperative bleeding with cardiac surgery. Transfusion. 2008;48:2S-30S

2. Paparella D, Brister SJ, Buchanan MR. Coagulation disorders of cardiopulmonary bypass: a review. Intensive Care Med. 2004;30:1873-81.

3. Karkouti K, Callum J, Crowther MA, McCluskey SA, Pendergrast J, Tait G, et al. The relationship between fibrinogen levels after cardiopulmonary bypass and large volume red cell transfusion in cardiac surgery: an observational study Anesth Analg. 2013;117:14-22.

4. Weber CF, Klages M, Zacharowski K. Perioperative coagulation management during cardiac surgery. Curr Opin Anaesthesiol. 2013;26:60-4.

5. Christensen MC, Krapf S, Kempel A, von Heymann C. Costs of excessive postoperative hemorrhage in cardiac surgery. J Thorac Cardiovasc Surg. 2009; 138:687-93

6. Karkouti K, Wijeysundera DN, Yau TM, Beattie WS, Abdelnaem E, McCluskey SA, et al. The independent association of massive blood loss with mortality in cardiac surgery. Transfusion. 2004;44:1453-62.

7. Vivacqua A, Koch CG, Yousuf AM, Nowicki ER, Houghtaling PL, Blackstone EH, et al. Morbidity of bleeding after cardiac surgery: is it blood transfusion, reoperation for bleeding, or both? Ann Thorac Surg. 2011;91:1780-90.

8. Alfirevic A, Xu M, Johnston D, Figueroa P, Koch CG. Transfusion increases the risk for vasoplegia after cardiac operations. Ann Thorac Surg. 2011;92:812-9.

9. Bilgin YM, van de Watering LMG, Versteegh MIM, van Oers MHJ, Vamvakas EC, Brand A. Postoperative complications associated with transfusion of platelets and plasma in cardiac surgery. Transfusion. 2011;51:2603-10.

10. Ranucci M, Pazzaglia A, Bianchini C, Bozzetti G, Isgro G. Body size, gender, and transfusions as determinants of outcome after coronary operations. Ann Thorac Surg. 2008;85:481-6.

11. Society of Thoracic Surgeons Blood Conservation Guideline Task Force, Ferraris VA, Brown JR, Despotis GJ, Hammon JW, Reece TB, Saha SP, et al. 2011 update to the Society of Thoracic Surgeons and the Society of Cardiovascular Anesthesiologists blood conservation clinical practice guidelines. Ann Thorac Surg. 2011;91:944-82.

12. Halkos ME, Levy JH, Chen E, Reddy VS, Lattouf OM, Guyton RA, et al Early experience with activated recombinant factor VII for intractable hemorrhage after cardiovascular surgery. Ann Thorac Surg. 2005;79:1303-6.

13. Hardy J-F, Belisle S, Van der Linden P. Efficacy and safety of activated recombinant factor VII in cardiac surgical patients. Curr Opin Anaesthesiol. 2009;22:95-9.

14. Karkouti K, Beattie WS, Arellano R, Aye T, Bussieres JS, Callum JL, et al. Comprehensive Canadian review of the off-label use of recombinant activated factor VII in cardiac surgery. Circulation. 2008;118:331-8. 
15. Karkouti K, Beattie WS, Wijeysundera DN, Yau TM, McCluskey SA, Ghannam M, et al. Recombinant factor VIIa for intractable blood loss after cardiac surgery: a propensity score-matched case-control analysis. Transfusion. 2005;45:26-34.

16. O'Connell KA, Wood JJ, Wise RP, Lozier JN, Braun MM. Thromboembolic adverse events after use of recombinant human coagulation factor VIIa. JAMA. 2006;295:293-8.

17. Romagnoli S, Bevilacqua S, Gelsomino S, Pradella S, Ghilli L, Rostagno C, et al. Small-dose recombinant activated factor VII (NovoSeven) in cardiac surgery. Anesth Analg. 2006;102:1320-6.

18. von Heymann C, Hotz H, Konertz W, Kox WJ, Spies C. Successful treatment of refractory bleeding with recombinant factor VIIa after redo coronary artery bypass graft surgery. J Cardiothorac Vasc Anesth. 2002;16:615-6.

19. Warren O, Mandal K, Hadjianastassiou V, Knowlton L, Panesar S, John K, et al. Recombinant activated factor VII in cardiac surgery: a systematic review. Ann Thorac Surg. 2007;83:707-14.

20. Petricevic M, Biocina B, Konosic S, Burcar I. Haemostatic management in high-risk cardiac surgery: a role of recombinant factor VIIa (NovoSeven RT). Eur J Cardiothorac Surg. 2012;42:606-7.

21. Cromwell C, Aledort LM. FEIBA: a prohemostatic agent. Semin Thromb Hemost. 2012;38:265-7.

22. Green D. Complications associated with the treatment of haemophiliacs with inhibitors. Haemophilia. 1999;5(Suppl 3):11-7.

23. Hilgartner MW, Knatterud GL. The use of factor eight inhibitor by-passing activity (FEIBA immuno) product for treatment of bleeding episodes in hemophiliacs with inhibitors. Blood. 1983;61:36-40.
24. Kurczynski EM, Penner JA. Activated prothrombin concentrate for patients with factor VIII inhibitors. N Engl J Med. 1974;291:164-7.

25. Leissinger CA, Blatt PM, Hoots WK, Ewenstein B. Role of prothrombin complex concentrates in reversing warfarin anticoagulation: a review of the literature. Am J Hematol. 2008;83:137-43.

26. Makris M, Greaves M, Phillips WS, Kitchen S, Rosendaal FR, Preston EF. Emergency oral anticoagulant reversal: the relative efficacy of infusions of fresh frozen plasma and clotting factor concentrate on correction of the coagulopathy. Thromb Haemost. 1997;77:477-80.

27. Demeyere R, Gillardin S, Arnout J, Strengers PF. Comparison of fresh frozen plasma and prothrombin complex concentrate for the reversal of oral anticoagulants in patients undergoing cardiopulmonary bypass surgery: a randomized study. Vox Sang. 2010;99:251-60.

28. Turecek PL, Varadi K, Gritsch H, Schwarz HP. FEIBA: mode of action. Haemophilia. 2004;10(Suppl 2):3-9.

29. Astermark J, Donfield SM, DiMichele DM, Gringeri A, Gilbert SA, Waters J, et al. A randomized comparison of bypassing agents in hemophilia complicated by an inhibitor: the FEIBA NovoSeven Comparative (FENOC) Study. Blood. 2007;109:546-51.

30. Bonnet PO, Yoon BS, Wong WY, Boswell K, Ewenstein BM. Cost minimization analysis to compare activated prothrombin complex concentrate and recombinant factor VIIa for haemophilia patients with inhibitors undergoing major orthopaedic surgeries. Haemophilia. 2009;15:1083-9.

31. Diprose P, Herbertson MJ, O'Shaughnessy D, Gill RS. Activated recombinant factor VII after cardiopulmonary bypass reduces allogeneic transfusion in complex non-coronary cardiac surgery: randomized double-blind placebo-controlled pilot study. Br J Anaesth. 2005;95:596-602. 